\title{
House dust mite induces direct airway inflammation in vivo: implications for future disease therapy?
}

\author{
J. De Alba*\#, K. Raemdonck*,", A. Dekkak*\#, M. Collins*,\#, S. Wong*,\#, A.T. Nials", \\ R.G. Knowles", M.G. Belvisi, ${ }^{*}$ and M.A. Birrell*,\#
}

ABSTRACT: House dust mite (HDM) is the major source of allergen in house dust and is strongly associated with the development of asthma. HDM can evoke a direct, nonallergic inflammatory reaction in vitro. We aimed to determine whether this apparent nonallergic, inflammatory response can be observed in a more complex in vivo setting.

Vehicle, Alum ${ }^{\mathrm{TM}}$ or HDM (Dermatophagoides pteronyssinus $5 \mu \mathrm{g}$, i.p. with Alum) sensitised Brown-Norway rats were challenged intratracheally with vehicle (saline), HDM (Der $p 10 \mu \mathrm{g}$ ) or heat-inactivated HDM on day 21. Lung function changes and the associated inflammatory response were evaluated.

Tissue and bronchoalveolar lavage from Alum ${ }^{\mathrm{TM}}$ sensitised Der $p$ challenged animals exhibited strong eosinophilia and neutrophilia associated with an early release of pro-inflammatory cytokines (interleukin-13 and $1 \beta$, eotaxin and thymus and activation-regulated chemokine). This response was not attenuated by removal of HDM-associated protease activity. Interestingly, the vehicle sensitised group (no Alum ${ }^{\mathrm{TM}}$ ) lacked this inflammatory response.

HDM allergen evokes nonallergic airways inflammation with an inflammatory profile similar to that of the asthmatic airway. This response, independent of the protease activity of the HDM extract, appeared to be linked to prior administration of the adjuvant Alum ${ }^{\mathrm{TM}}$ and the subsequent increase in total immunoglobulin $\mathrm{E}$. This finding could have important implications in the development of future asthma therapies.

KEYWORDS: Allergy, asthma, cytokines, house dust mite, inflammation, rodent

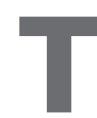
he exposure to house dust mite (HDM) allergens is strongly associated with the development of allergic diseases, such as asthma, rhinitis or atopic dermatitis [1, 2]. Mites from the genus Dermatophagoides, such as $D$. pteronyssinus (Der $p$ ) and D. farinae (Der $f)$, are thought to be the most important source of indoor allergens associated with human asthma [1, 3]. Over 30 proteins produced by Dermatophagoides mites induce immunoglobulin (Ig)E in allergic patients, but there are dominant antigens, especially the group 1 and 2 allergens, which can account for the bulk of allergenicity of HDM extracts [1]. Among the group 1 allergens is Der $p 1$ from $D$. pteronyssinus. Der $p 1$ belongs to the papain-like cysteine protease family and exhibits cysteine protease activity [4]. This proteolytic activity has been suggested to be involved in the pathogenesis of allergies by: increasing the permeability of epithelial cells and allowing the passage of their own and other allergens across the epithelium [5-7]; cleaving and/or interacting with cell surface molecules and intrinsic protease inhibitors [8-11]; and modulating the function of a range of cells, such as basophils, mast cells, alveolar macrophages and airway epithelial cells [12-15]. The effect on the airway epithelium is especially interesting, as it is likely to be the first cell type to interact with the allergen. Several authors have reported that $\operatorname{Der} p 1$ and other Der $p$ antigens are able to directly induce the release of pro-inflammatory cytokines and chemokines from primary human bronchial epithelial cells and airway epithelial cell lines [14, 16-20] by protease-dependent and independent mechanisms [14, 16, 19, 21].

To our knowledge, however, this pro-inflammatory effect of HDM has not been shown in a more complex in vivo system. Therefore, our objective was to investigate whether a commercial HDM extract from $D$. pteronyssinus was able to elicit a direct nonallergic, pro-inflammatory effect in the Brown-Norway $(\mathrm{BN})$ rat. The $\mathrm{BN}$ rat was chosen
AFFILIATIONS

*Respiratory Pharmacology, Pharmacology and Toxicology, Imperial College London, Faculty of Medicine, National Heart and Lung Institute, and

${ }^{*}$ Centre for Integrative Mammalian Physiology and Pharmacology, Imperial College, London, and "Respiratory Centre of Excellence for Drug Discovery, GlaxoSmithKline, Research and Development, Medicines Research Centre, Stevenage, UK.

CORRESPONDENCE

M. Belvisi

Respiratory Pharmacology, Pharmacology and Toxicology, Faculty of Medicine, National Heart and Lung Institute, Imperial College Sir Alexander Fleming Building Exhibition Road

London

SW7 2AZ

UK

E-mail: m.belvisi@imperial.ac.uk

Received:

Feb 132008

Accepted after revision:

Sept 292009

First published online:

Oct 192009 
because we, and others, have previously demonstrated that an allergic reaction to other antigens, i.e. ovalbumin (OVA), is achievable in this strain [22].

\section{METHODS}

\section{Animals}

Male BN rats (200-225 g) were obtained from Charles River Laboratories Inc. (Lyon, France) and housed for 1 week before initiating experiments.

\section{HDM extract}

Purified HDM extract from Der $p$ (GREER laboratories, Lenoir, NC, USA) with a known content of Der $p 1\left(39.77 \mu \mathrm{g} \cdot \mathrm{mg}^{-1}\right.$ dry weight) was used in these experiments. The doses of HDM used in this manuscript refer to the amount of Der $p 1$.

\section{Measurement of protease activity in the extract}

Protease activity in the extract was assessed by a continuous rate (kinetic) assay using the fluorogenic peptide substrate BocGln-Ala-Arg-AMC (AMC, 7-amino-4-methylcoumarin; Boc, Ntert-butoxycarbonyl) as previously described [23]. Briefly, a known amount of HDM extract (final concentration Der $p 1$ $10 \mathrm{nM})$ was added to a substrate standard curve $(0-1 \mathrm{mM})$, in $50 \mathrm{mM}$ sodium phosphate buffer ( $\mathrm{pH} 7.0$ ) containing $1 \mathrm{mM}$ EDTA and $1 \mathrm{mM}$ dithiothreitol at $25^{\circ} \mathrm{C}$. Fluorescence associated with the hydrolysis of the substrate was monitored using a Synergy ${ }^{\mathrm{TM}}$ HT Multi-Mode Microplate Reader (Biotek UK, Potton, UK) with $\lambda \mathrm{ex}=380 \mathrm{~nm}$ and $\lambda \mathrm{em}=460 \mathrm{~nm}$. Data were fitted to a Michaelis-Menten equation, $\mathrm{y}=\mathrm{V} \times \mathrm{x}$ / $(\mathrm{Km}+\mathrm{x})$, and the kinetic constants $\mathrm{Km}$ (Michaelis-Menten constant) and maximal rate of conversion $\left(V^{\prime} \max \right)$ were calculated. HDM extract showed a positive protease activity with a $V^{\prime} \max$ of $76,636 \mu \mathrm{mol} \cdot \mathrm{min}^{-1}$ and a $\mathrm{Km}$ of $304.9 \mu \mathrm{M}$. As a control, a similar amount of HDM extract was inactivated by heating to $65^{\circ} \mathrm{C}$ for $30 \mathrm{~min}$, as previously described [19].

\section{Dosing route selection}

The majority of our previous work into allergic airway inflammation has involved aerosolised challenging with the antigen. Unfortunately, we were unable to utilise this method because of the cost implications. Therefore, our initial aim was to determine the optimum topical route of administration for the allergen by comparing the intranasal and intratracheal routes. This was carried out by using lipopolysaccharide (LPS)induced tumour necrosis factor (TNF)- $\alpha$ release in the lung as a biomarker of appropriate delivery. Male BN rats (200-225 g) were anaesthetised ( $4 \%$ halothane in oxygen for $3 \mathrm{~min}$ ) and vehicle (saline) or LPS $\left(100 \mu \mathrm{g} \cdot \mathrm{rat}^{-1}\right.$, i.e. the same amount in each case) were administered in various volumes either intranasally $(5,10,20,50$ or $100 \mu \mathrm{L}$ in each nostril), using a pipette in a drop-wise fashion, or intratracheally $(250 \mu \mathrm{L})$. After 90 mins blood, lavage and lung tissue samples were taken. TNF- $\alpha$ was measured by ELISA (R\&D systems Inc., Minneapolis, MN, USA) as described in the study by BIRRELL et al. [24].

\section{HDM sensitising dose selection}

Times for sensitisation challenge were extrapolated from our OVA allergic inflammation model in the BN rat [24]. An allergen dose-response study was performed to evaluate the optimum sensitising dose by measuring the levels of
HDM-specific IgE in plasma 14 days after i.p. dosing. Male BN rats $(200-225 \mathrm{~g})$ were sensitised on day 0 with saline, Alum ${ }^{\mathrm{TM}}$ (Fisher Scientific UK Ltd, Loughborough, UK) or HDM extract (0.5-500 $\mu \mathrm{g} \cdot \mathrm{rat}^{-1}$, i.p.; GREER laboratories) administered with Alum $^{\mathrm{TM}}$. At day 14 blood samples were collected and the plasma separated.

ELISA plates (Nunc MAXsorb; Fisher Scientific) were coated with $50 \mu \mathrm{L}$ of $5 \mu \mathrm{g} \cdot \mathrm{mL}^{-1} \mathrm{HDM}$ protein in PBS and left overnight at room temperature. Plates were then washed with wash buffer (Invitrogen, Paisley, UK) and blocked for at least $30 \mathrm{~min}$ with $4 \%$ bovine serum albumin (BSA; Sigma Aldrich, Poole, UK) in PBS. Plasma samples were then added to duplicate wells diluted 1:10 in PBS containing 4\% BSA and 0.05\% Tween 20. They were then incubated overnight at room temperature prior to adding biotinylated anti-IgE (1:10; Serotec, Kidlington, UK) at $2 \mu \mathrm{g} \cdot \mathrm{mL}^{-1}$ (in PBS containing $4 \%$ BSA and $0.05 \%$ Tween 20) and further incubated for $1 \mathrm{~h}$ at room temperature. After washing, plates were incubated for $30 \mathrm{~min}$ at room temperature with horseradish peroxidase-streptavidin (1:4000; Amersham Biosciences, Uppsala, Sweden). Following a last wash, tetramethylbenzidine substrate (Sigma Aldrich) was added to the plates and they were incubated at room temperature until colour developed. The reaction was stopped with $0.25 \mathrm{M}$ sulphuric acid and plates were read at $450 \mathrm{nM}$ (Biotek Powerwave XS plate reader; Biotek UK). Total IgE was measured using a commercial rat IgE quantitative ELISA kit (Bethyl Laboratories, Montgomery, TX, USA) following the protocol of the manufacturer and expressed as $\mu \mathrm{g} \cdot \mathrm{mg}^{-1}$ of lung tissue total protein.

\section{HDM challenging dose selection}

Following the determination of the optimal sensitising dose, we aimed to determine an appropriate HDM dose for challenging previously sensitised animals. Male $\mathrm{BN}$ rats (200-225 g) were sensitised at day 0 and 14 with HDM $\left(5 \mu \mathrm{g} \cdot \mathrm{rat}^{-1}\right.$, i.p. $)$ administered with Alum $^{\mathrm{TM}}$. Rats were then challenged with intratracheal vehicle (saline) or HDM (0.1$100 \mu \mathrm{g} \cdot$ rat $^{-1}$ in $250 \mu \mathrm{L}$ saline) on day 21 .

$48 \mathrm{~h}$ after HDM challenge, rats were lavaged $(2 \times 3 \mathrm{~mL}$ RPMI). Total cell counts recovered from the airway lumen were quantified using a Sysmex cell counter (Sysmex UK Ltd, Milton Keynes, UK). Differential cell counts (eosinophils, neutrophils and lymphomononuclear cells expressed as absolute cell counts) of cells recovered from the airway lumen were made by light microscopy after Wright-Giemsa staining using standard morphological criteria.

\section{Time course after HDM sensitisation/challenge on cell recruitment in the $B N$ model}

To determine the effect of the acute exposure to HDM on asthma-like end-points, male BN rats (150-180 g) were sensitised on day 0 and 14 with vehicle (saline) or HDM extract $\left(5 \mu \mathrm{g} \cdot\right.$ rat $^{-1}$, i.p.) administered with Alum ${ }^{\mathrm{TM}}$. Rats were challenged with intratracheal vehicle (saline) or HDM extract (10 $\mu \mathrm{g}$ intratracheal) on day 21 .

Animals were lavaged 6, 24 or $48 \mathrm{~h}$ later and differential white cell counts were performed as described above. Similarly white cell numbers and type in the lung tissue were determined as described previously [24]. The remaining lung was either 
snap-frozen or fixed in formalin for histological assessment. Inflammatory mRNA/protein expression was assessed by real-time PCR using fully validated primers and probes as detailed in MCCLUSKIE et al. [25] or by specific ELISA (R\&D Systems Inc.), respectively. Cytokine location in the lung was visualised using immunohistochemistry.

Briefly, insufflated formalin fixed lung tissues were processed and wax embedded. $4-\mu \mathrm{m}$ sections of paraffin embedded tissue were dewaxed and rehydrated. Intrinsic peroxidase activity was blocked by incubating the sections with $3 \%$ hydrogen peroxide (interleukin (IL)-13; $25 \mathrm{~min}$ ) or 2\% hydrogen peroxide (eotaxin and IL-1 $\beta ; 20 \mathrm{~min}$ ). IL-13 and IL-1 $\beta$ slides were then subjected to antigen retrieval by pressure cooking in sodium citrate buffer (10 mM; pH 6.0). Nonspecific binding was reduced with $10 \%$ normal rabbit serum (Vector Laboratories, Burlingame, CA, USA) in PBS containing $0.1 \%$ BSA and $0.025 \%$ Tween 80 for 20 min for IL-13 immunohistochemistry and 1\% normal rabbit serum (Dako UK Ltd, Ely, UK) in PBS containing $0.1 \%$ BSA and $0.025 \%$ Tween 80 for $20 \mathrm{~min}$ for eotaxin and IL-1 $\beta$ immunohistochemistry. Sections were then rinsed and the primary antibody (goat polyclonal anti-mouse IL-13 antibody, 1:250 dilution (Santa Cruz Biotechnology, Santa Cruz, CA, USA); goat polyclonal antimouse eotaxin/CCL11, 1:50 dilution (R\&D Systems Inc); or goat polyclonal anti-rat IL-1 $\beta$, 1:200 dilution (Santa Cruz
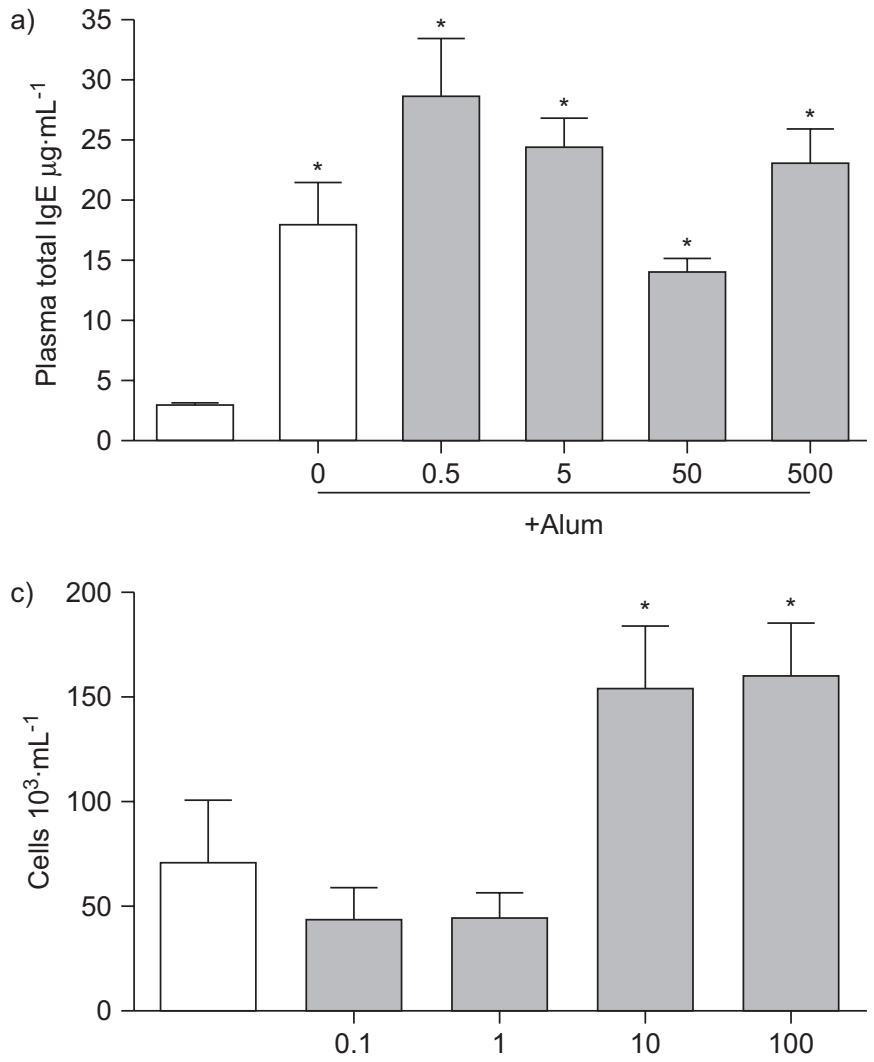

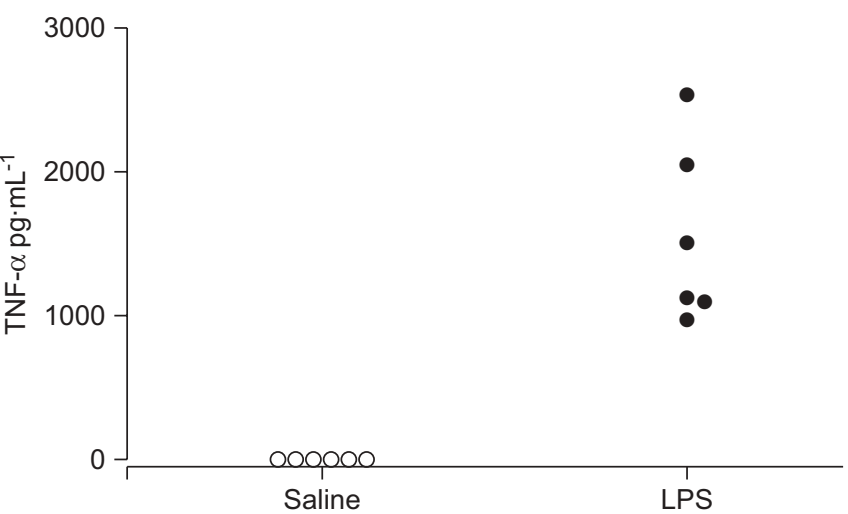

FIGURE 1. Data to show that intratracheal delivery is a robust route for lung delivery. $250 \mu \mathrm{L}$ of vehicle (saline) or lipopolysaccharide (LPS) was dosed intratracheally to anaesthetised rats $90 \mathrm{~min}$ before bronchoalveolar lavage fluid collection. Tumour necrosis factor (TNF)- $\alpha$ levels were measured by ELISA.

Biotechnology)) diluted in PBS containing 0.1\% BSA and $0.025 \%$ Tween 80 was applied for $1 \mathrm{~h}$ at room temperature. Sections were then incubated with a secondary biotinylated rabbit anti-goat IgG (IL-13: 1:150 dilution for 30 min; eotaxin: 1:100 for $60 \mathrm{~min}$; IL-1 $\beta$ : 1:120 for $60 \mathrm{~min}$; Vector Laboratories) followed by detection with a Vectastain Elite $A B C$ kit for
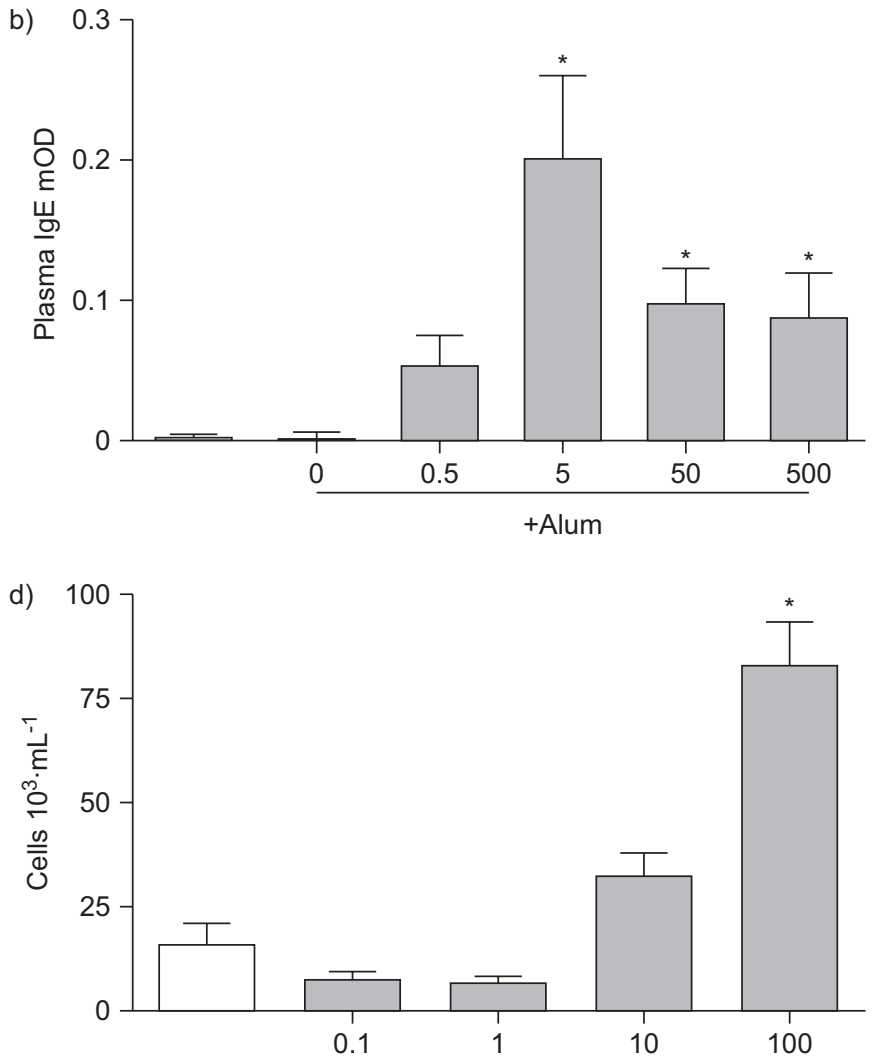

FIGURE 2. Determining the optimum sensitising and challenging dose of house dust mite (HDM). a, b) Brown-Norway rats were sensitised with vehicle ( $\square$ ) (with and without Alum ${ }^{\mathrm{TM}}$ ) or increasing doses of HDM (Der p1) (with Alum ${ }^{\mathrm{TM}}$ ) ( $(\mathbf{\square})$. Plasma samples were collected after 14 days for measurement of a) total immunoglobulin (Ig)E and b) HDM-specific IgE. c, d) A second set of animals were sensitised with HDM (5 $\mu$ g, i.p.) plus Alum ${ }^{\text {TM }}$ on days 0 and 14.7 days later they were challenged with vehicle or increasing doses of HDM. The lungs were lavaged 2 days after challenge and the number of $\mathrm{c}$ ) bronchoalveolar lavage eosinophils and d) bronchoalveolar lavage neutrophils were determined. Data $(n=6-8)$ are presented as mean \pm SEM and were analysed by one-way ANOVA followed by a Dunnett's post test. *: $p<0.05$. 

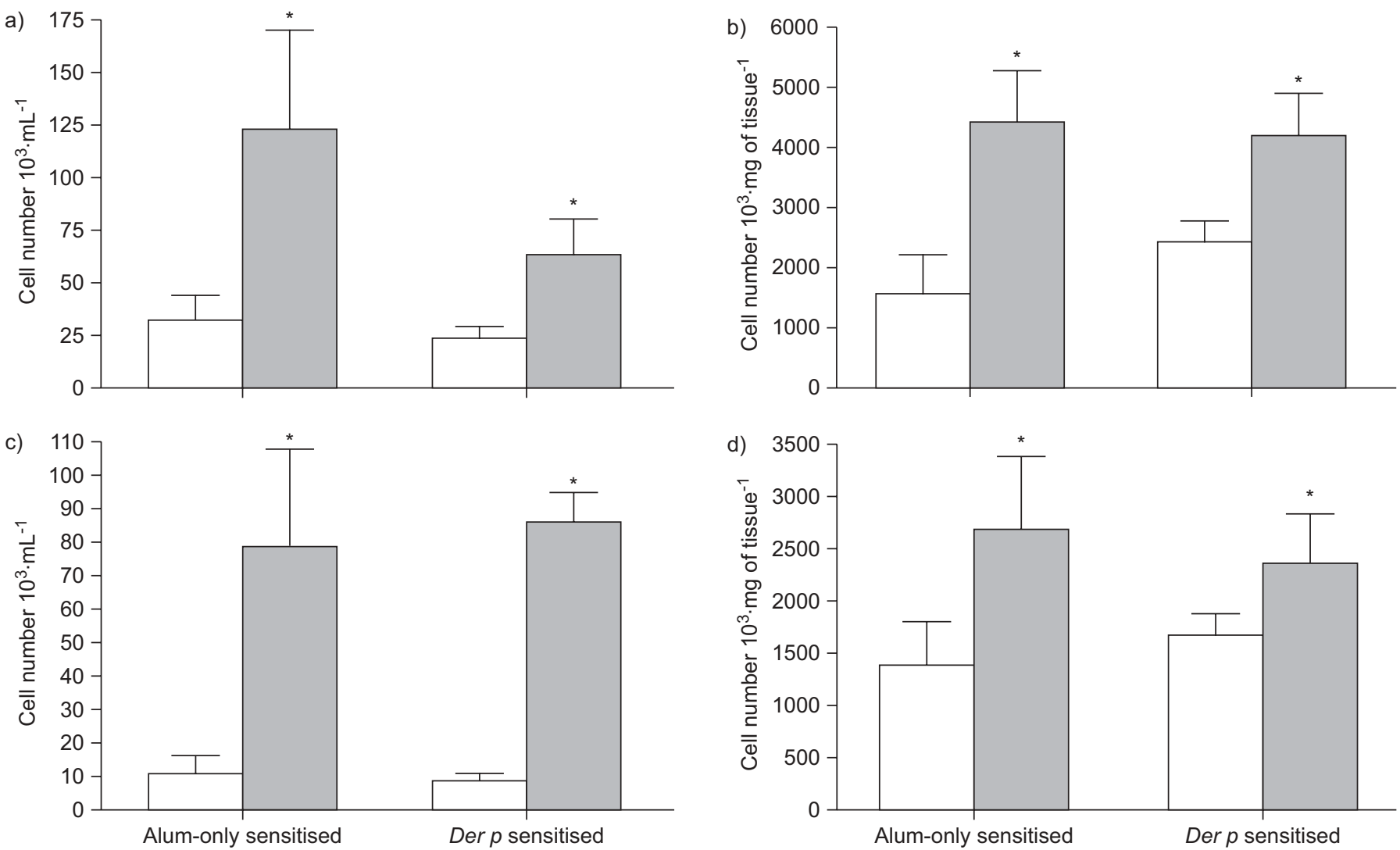

FIGURE 3. The effect of house dust mite (HDM) challenge on cell recruitment in the bronchoalveolar lavage (BAL) and lung tissue time course. Brown-Norway rats were sensitised with Alum ${ }^{\text {TM }}$ only or $\operatorname{HDM}\left(5 \mu\right.$ g, i.p.) plus Alum ${ }^{\text {TM }}$ on days 0 and 14. They were challenged 7 days later with vehicle ( $\square$ ) or HDM (10 $\mu$ g intratracheal; $\square$ ). BAL fluid and lung tissue were collected 6,24 and $48 \mathrm{~h}$ later. Data are presented for a) BAL eosinophils and c) BAL neutrophils, and b) lung tissue eosinophils and d) lung tissue neutrophils $48 \mathrm{~h}$ after challenge. Data $(n=4-8)$ are presented as mean \pm SEM and were analysed using the Mann-Whitney test. *: $p<0.05$.

mouse IgG (PK6102; Vector Laboratories). The staining was revealed using the diaminobenzidine (Sigma Aldrich) procedure counterstaining with Mayer's haematoxylin. Tissues incubated with a blocking peptide instead of the primary peptide were used as negative controls.

Images were captured using an Olympus BX-51 microscope (Olympus UK Ltd, Southend-on-sea, UK) fitted for both transmitted light and fluorescence imaging and a Qicam digital camera (Qimaging, Surrey, BC, Canada).

\section{Noninvasive determination of the late bronchoconstrictor response to HDM challenge}

After HDM challenge, conscious and unrestrained vehicle or HDM sensitised rats were placed in a whole-body plethysmograph (Buxco Research Systems, UK) and pressure changes were continuously registered by a Buxco XA-analyser (Buxco Research Systems). Enhanced pause (Penh) was recorded for $\leqslant 5 \mathrm{~h}$ and mean values were taken in 10-min intervals. A baseline value was obtained by recording the Penh for $10 \mathrm{~min}$ $24 \mathrm{~h}$ before the challenge and baseline corrected values were used for analysis.

\section{Invasive determination of changes in airway resistance in response to HDM challenge}

Because of the controversy associated with using whole-body plethysmograph (Penh) as a lung function measurement [26], we confirmed our results using conventional invasive lung mechanics. Vehicle or HDM sensitised male BN rats were anaesthetised (ketamine and xylazine 144 and $10 \mathrm{mg} \cdot \mathrm{kg}^{-1}$, respectively, i.p.) and instrumented $48 \mathrm{~h}$ after challenge. Briefly, the trachea was cannulated and the animal artificially respired with a tidal volume of $2 \mathrm{~mL} \cdot \mathrm{kg}^{-1}$ at a frequency of 90 breaths $\cdot \mathrm{min}^{-1}$. A water-filled oesophageal cannula was inserted such that an estimate of transpulmonary pressure could be recorded. Pulmonary resistance $\left(\mathrm{cmH}_{2} \mathrm{O} \cdot \mathrm{mL}^{-1} \cdot \mathrm{s}^{-1}\right)$ and dynamic compliance $\left(\mathrm{mL} \cdot \mathrm{cmH}_{2} \mathrm{O}^{-1}\right)$ were continuously computed on a Buxco XA-analyser (Buxco Electronics). Administration of aerosolised spasmogen was via a nebuliser (Buxco Electronics) connected in line with the ventilator. Airway responsiveness was assessed by nebulising increasing concentrations of methacholine (100 $\mu \mathrm{L}$ of vehicle (saline) 2,4 , 8,16 and $32 \mathrm{mg} \cdot \mathrm{mL}^{-1}$ ). Mean changes in airway resistance were monitored for $2 \mathrm{~min}$ after each administration of methacholine.

\section{Recall challenge of splenocytes from sensitised animals}

Male BN rats (150-180 g) were "sensitised" on days 0 and 14 with saline (i.p.) or Alum ${ }^{\mathrm{TM}}\left(20 \mathrm{mg} \cdot \mathrm{rat}^{-1}\right.$ aluminium hydroxide and $20 \mathrm{mg} \cdot$ rat $^{-1}$ magnesium hydroxide, i.p.). In parallel, as a control for the recall challenge, animals were sensitised with OVA as previously described [22]. Spleens were removed on day 21 after an overdose of pentobarbitone $\left(200 \mathrm{mg} \cdot \mathrm{kg}^{-1}\right.$, i.p. $)$, 

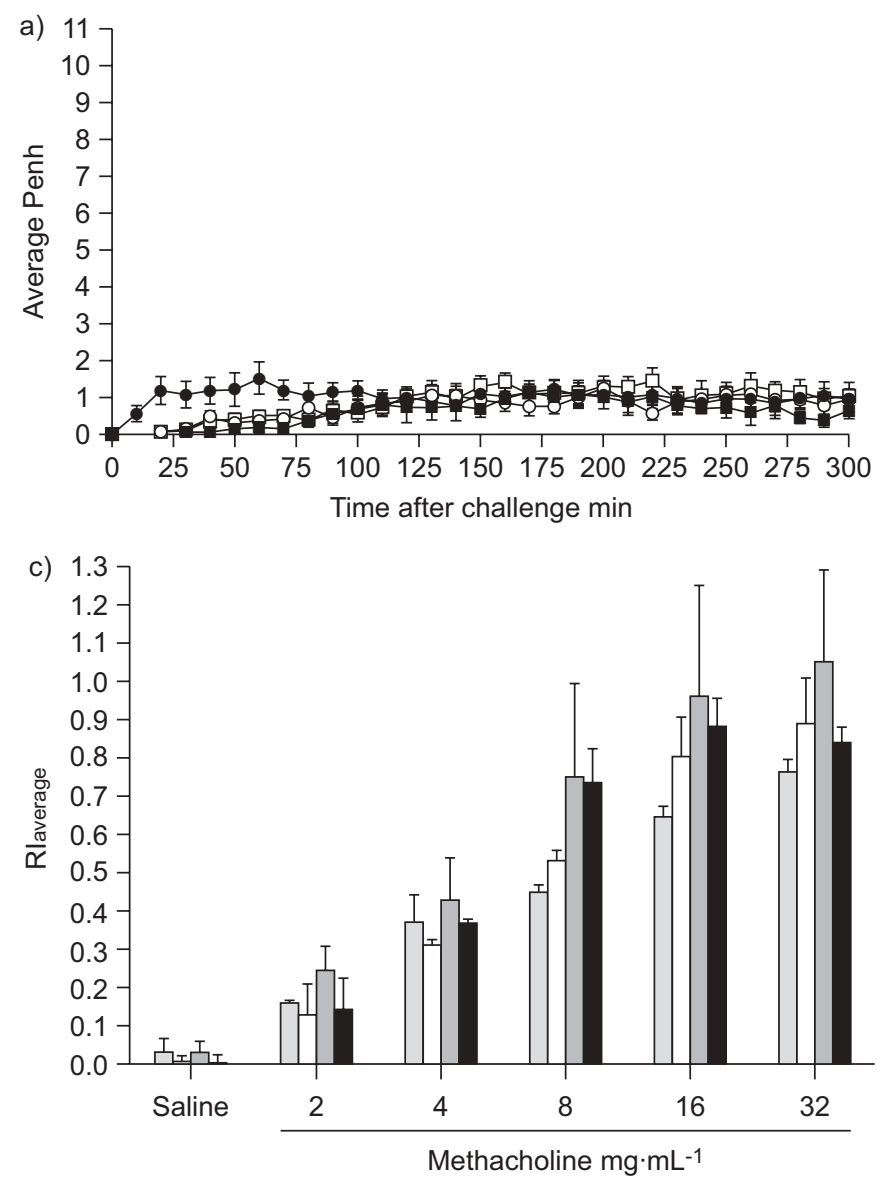

and transferred to cold PBS. They were then flushed with PBS using a needle and syringe (without calcium and magnesium; Sigma Aldrich), in order to obtain a splenocyte suspension. The pooled cell suspension was passed through a $70-\mu \mathrm{m}$ cell sieve and centrifuged at $250 \times g$ for $5 \mathrm{~min}$ at $4^{\circ} \mathrm{C}$ in a chill spin (Mistral 3000i; MSE, London, UK). The supernatant was discarded and the cell pellets were resuspended in PBS and then centrifuged. Splenocytes were then resuspended in RPMI 1640, supplemented with $10 \%$ fetal calf serum (FCS) and 1\% antibiotic and antimycotic solution (penicillin/streptomycin; Sigma Aldrich), counted and cell viability was determined using Trypan Blue. The splenocytes were diluted in RPMI 1640, supplemented with $10 \%$ FCS and $1 \%$ antibiotic and antimycotic solution, and $225 \mu \mathrm{L}$ of cells $\left(8 \times 10^{5}\right)$ were cultured in 24-well plates. To each well, $250 \mu \mathrm{L}$ of RPMI 1640, supplemented with $10 \%$ FCS and 1\% antibiotic and antimycotic solution, with $0.1 \%$ (volume/volume) dimethyl sulfoxide, was added. $25 \mu \mathrm{L}$ of varying concentrations of HDM (der $p$ 0.01$\left.50 \mu \mathrm{g} \cdot \mathrm{mL}^{-1}\right)$, OVA $\left(1 \mathrm{mg} \cdot \mathrm{mL}^{-1}\right)$ or saline were added to the corresponding wells. $200 \mu \mathrm{L}$ of cells were added to chamber slides. The plates and chamber slides were incubated for $72 \mathrm{~h}$ at $37^{\circ} \mathrm{C}$ in a humidified atmosphere $(95 \%$ air, $5 \%(\mathrm{v} / \mathrm{v})$ $\mathrm{CO}_{2}$ ). Supernatants were collected and cytokine release measured by specific ELISA (R\&D Systems Inc.).

\section{Data analysis}

All the values in the figures and text are presented as mean \pm SEM of $n$ observations. An unpaired t-test was used b)

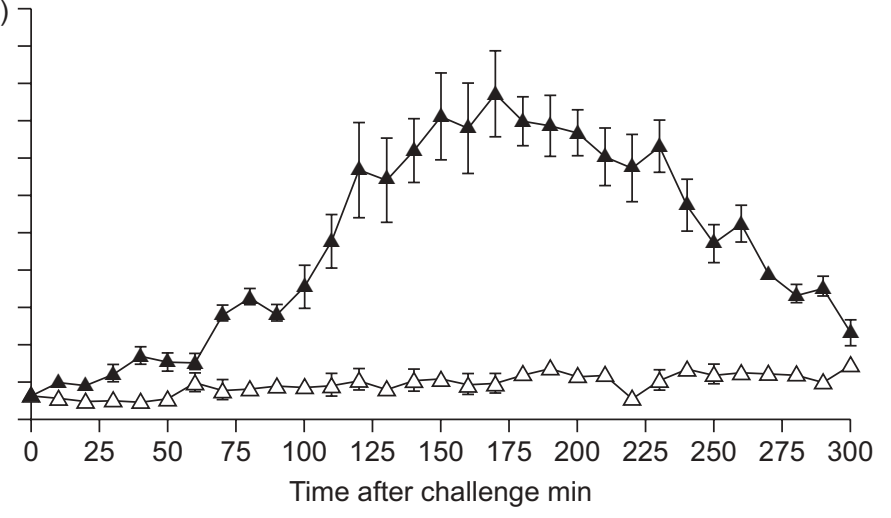

FIGURE 4. The effect of house dust mite (HDM) challenge on lung function. a) The absence of late asthmatic response (LAR) after HDM challenge in Alum ${ }^{\text {TM }}$ only or HDM plus Alum ${ }^{\mathrm{TM}}$ sensitised Brown-Norway rats. b) Typical LAR after ovalbumin (OVA) challenge in OVA sensitised Brown-Norway rats. The sensitisation/challenge regime was as follows: $\mathbf{\square}$ : Alum-only/vehicle; $\square$ : HDM+Alum/vehicle; $\bullet$ : HDM+Alum/ HDM; O: Alum-only/HDM; $\mathbf{A}$ : OVA/OVA; $\triangle$ : OVA/vehicle. The mean enhanced pause (Penh) was calculated at each 10-min interval for $5 \mathrm{~h}$. Baseline corrected values were used for analysis. Each time-point represents baseline corrected mean Penh \pm SEM. C) Changes in airway resistance in Alum only or HDM+Alum sensitised Brown-Norway rats following intratracheal HDM exposure. Invasive airway resistance was recorded using a Buxco LS20 system (Buxco Electronics, Wilmington, NC, USA). Average airway resistance $\left(\mathrm{cmH}_{2} \mathrm{O} \cdot \mathrm{mL}^{-1} \cdot \mathrm{s}^{-1}\right)$ was recorded for 2 min before increasing methacholine challenge concentration (2-32 $\left.\mathrm{mg} \cdot \mathrm{mL}^{-1}\right)$. Baseline corrected data are presented as mean \pm SEM. For all experiments $n=8$. $\square$ : Alum-only/vehicle; $\square$ : HDM+Alum/vehicle; $\mathbf{a}:$ Alum-only/HDM; $\mathbf{\square}:$ HDM+Alum/HDM. Rlaverage: average lung resistance.

when comparing two groups and a one-way ANOVA when comparing multiple groups with the appropriate post test. When data were found not to be normally distributed the Mann-Whitney test was used when comparing two groups and a Kruskal-Wallis test when comparing multiple groups with the appropriate post test. All treatments were compared to relevant vehicle control groups, differences were deemed significant when $\mathrm{p}<0.05$.

\section{RESULTS}

\section{Dosing route selection}

We found that in the rat, using LPS-induced TNF- $\alpha$ as a marker of successful lung delivery, intranasal dosing gave variable results (data not shown). Intratracheal delivery of LPS, however, resulted in a larger and more robust signal in all animals (fig. 1). Similar data were obtained when we analysed the lung tissue (not shown) and interestingly we could not detect any increase in plasma TNF- $\alpha$, even though if given intraperitoneally this dose would cause a massive increase in circulating TNF- $\alpha$ (data not shown).

Due to the variability associated with intranasal delivery we opted for the intratracheal route to deliver the HDM.

\section{HDM sensitising dose selection}

Plasma levels of total IgE were significantly increased 14 days after administration of Alum ${ }^{\mathrm{TM}}$ compared with vehicle only (saline) but were not further increased by co-administration with HDM extract (fig. 2a). HDM extract co-administration 

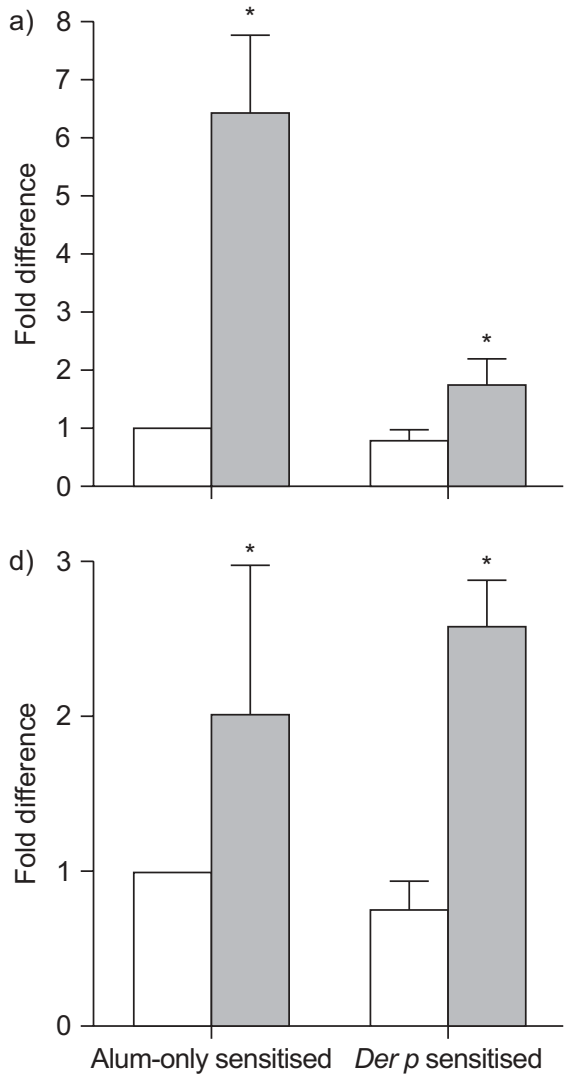
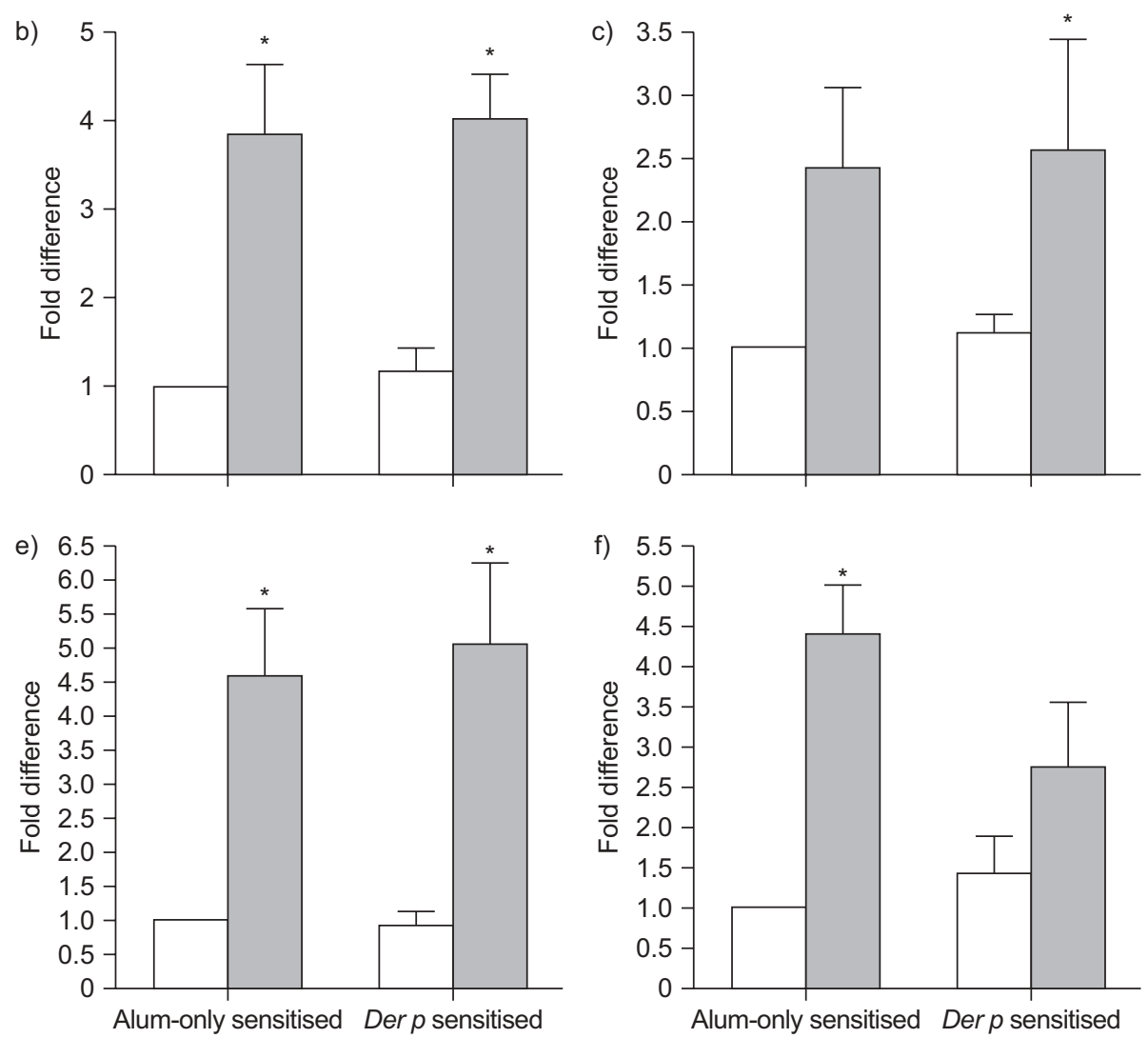

FIGURE 5. mRNA expression in lung tissue after house dust mite (HDM) challenge. Brown-Norway rats were sensitised with Alum only or HDM (5 $\mu$ g, i.p.) plus Alum on day 0 and 14 . They were challenged 7 days later with vehicle $(\square)$ or $\operatorname{HDM~}(10 \mu \mathrm{g}$ intratracheal; $\square)$. Lung tissue was collected 6,24 and $48 \mathrm{hlater}$. mRNA expression at $6 \mathrm{~h}$ is shown, as measured by real-time RT-PCR. a) Interleukin (IL)-13, b) IL-1 3, c) eotaxin, d) cytokine induced neutrophil chemoattractant-1, e) monocyte chemotactic protein-3 and $\mathrm{f})$ thymus and activation-regulated chemokine. Data $(n=4-8)$ are presented as mean \pm SEM. Statistics were performed on the raw data using either an unpaired t-test or the Mann-Whitney test depending on the distribution of the data. *: $p<0.05$ versus the corresponding control.

did, however, cause a significant increase in HDM-specific IgE plasma levels compared with Alum ${ }^{\mathrm{TM}}$ alone (fig. 2b).

$5 \mu \mathrm{g}$ of $\operatorname{Der} p 1$ induced a robust increase in specific IgE and we adopted this dose for further studies.

\section{HDM challenging dose selection}

Intratracheal challenge with HDM caused significant bronchoalveolar (BAL) fluid eosinophilia at the top two doses tested (fig. 2c). The eosinophilia was accompanied by a significant increase in neutrophil numbers at the highest dose (fig. 2d).

As $10 \mu \mathrm{g}$ of $\operatorname{Der} p 1$ induced eosinophilia with less marked neutrophilia we adopted this dose to further our investigations.

\section{Effect of HDM sensitisation/challenge on cell recruitment in BAL fluid and lung tissue}

6 and $48 \mathrm{~h}$ after challenge with HDM extract we could detect an increase in airway neutrophilia and eosinophilia, respectively, in both the BAL fluid and the lung tissue (fig. 3). Interestingly we observed similar magnitudes of inflammation in the Alum ${ }^{\mathrm{TM}}$-only sensitised animals to that seen in the rats previously sensitised with HDM. Animals sensitised only with vehicle (saline) showed no sign of inflammation in either BAL or tissue (data not shown). This observation would suggest that Alum ${ }^{\mathrm{TM}}$ is important in the direct inflammatory response to HDM.

\section{Effect of HDM sensitisation/challenge on airway function measurements}

There were no changes in airway function after challenge. Monitoring of late asthmatic response (LAR) after HDM/ vehicle challenge failed to show any significant differences between the groups studied (fig. 4a), whereas using our standard OVA driven model we can measure significant LAR in this strain of rats (fig. 4b) [24]. Similarly, there were no significant changes in the airway responsiveness to inhaled methacholine when measured $48 \mathrm{~h}$ after the challenge (fig. 4c).

\section{Effect of HDM sensitisation/challenge on cytokine/ chemokine gene expression and release}

To attempt to investigate the mechanism underlying the observed nonallergic inflammation we measured a range of asthma-linked inflammatory cytokines at the mRNA and protein level. The results showed an increase in inflammatory mRNA expression, such as IL-13, IL-1 $\beta$, eotaxin, thymus and activation-regulated chemokine (TARC), monocyte chemotactic protein (MCP)-3 and the rat equivalent of growth regulated oncogene (GRO)- $\alpha$, and cytokine-induced neutrophil chemoattractant (CINC)-1, $6 \mathrm{~h}$ after challenge (fig. 5). We 

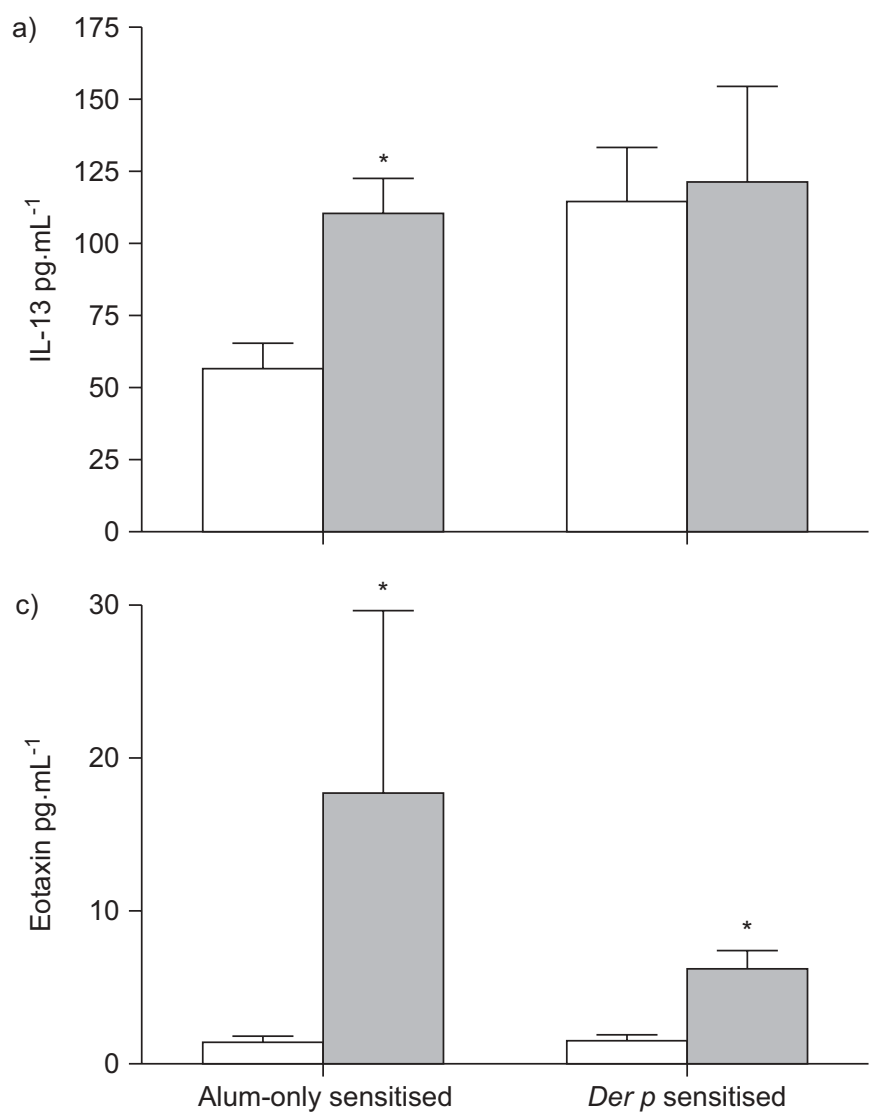
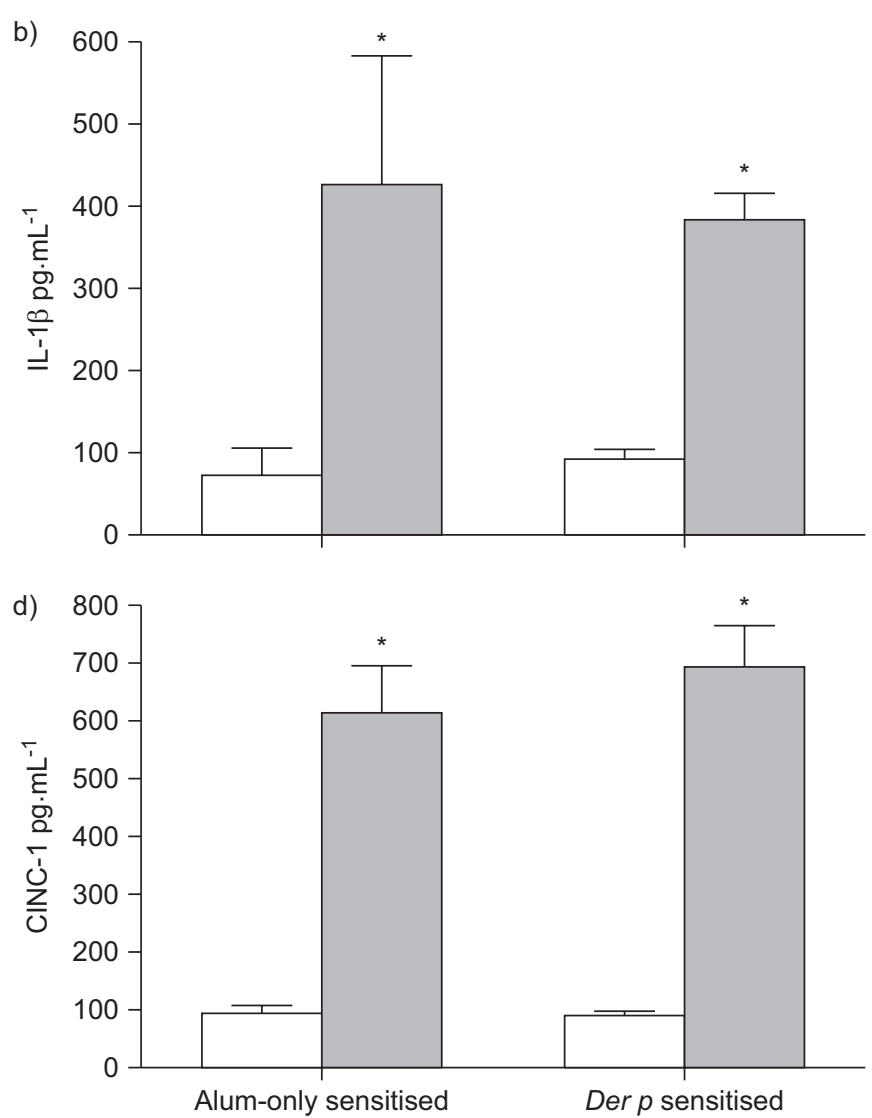

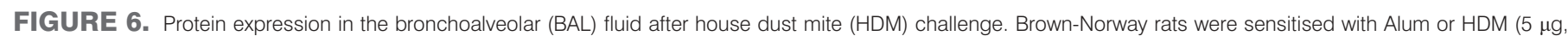

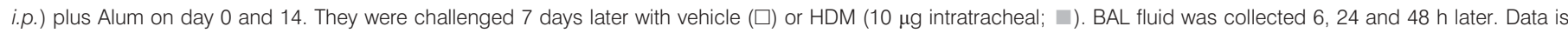

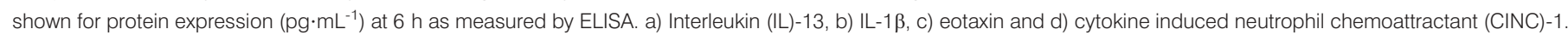

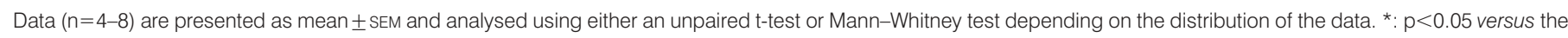
corresponding control.

found parallel increases in protein expression of the mediators we could measure using available rat ELISAs (fig. 6). As with the increase in cellular inflammation, HDM induced increases in inflammatory cytokines both in the HDM sensitised and the Alum $^{\mathrm{TM}}$-only sensitised rats. We could not detect any increase in IL- 4 and interferon- $\gamma$ in these samples.

A histological assessment of the lung tissue from saline sensitised/saline challenge shows no inflammatory infiltration in the lung parenchyma at $48 \mathrm{~h}$ (fig. 7a); whereas the timematched Alum-only sensitised/Der $p$ challenged animals showed the existence of inflammatory infiltration $48 \mathrm{~h}$ after challenge (fig. 7b).

Immunohistochemical staining demonstrated that the lungs of Alum-only sensitised/Der $p$ challenged animals show positive staining for IL-13 (fig. 7c and d) in the airway epithelium and in inflammatory cells resembling alveolar macrophages $6 \mathrm{~h}$ after challenge. In agreement with these findings, although IL13 is generally associated to T-cells and sometimes to mast cells or eosinophils, it has been recently reported that it can be also be associated with airway macrophages [27] and airway epithelial cells [28, 29]. Eotaxin was also highly expressed but mainly in the epithelium of large and small airways (fig. 7e and $\mathrm{f}$ ), while IL-1 $\beta$ staining was very low in the epithelium and it appeared to be mainly associated to the inflammatory cell infiltrate (fig. $7 \mathrm{~g}$ and $\mathrm{h}$ ).

\section{Effect of HDM protease activity on cell recruitment in BAL fluid and lung tissue}

In order to determine whether the protease activity of the HDM extract was responsible for the apparent direct inflammatory response observed previously, animals were "sensitised" either with vehicle (saline) or Alum ${ }^{\mathrm{TM}}$-only and then challenged intratracheally with either proteolytically active or heat-inactivated HDM extract (fig. 8a). Saline sensitised animals, unlike those that were sensitised with Alum ${ }^{\mathrm{TM}}$-only, did not exhibit airway inflammation (fig. 8b). Heat inactivated HDM extract was also able to elicit an inflammatory response in the Alum $^{\mathrm{TM}}$ sensitised animals but not in the saline sensitised animals (fig. 8b).

\section{Recall challenge of splenocytes from sensitised animals}

To discount that the response observed in the Alum ${ }^{\mathrm{TM}}$-only sensitised animals could be due to an undefined protein, which was then delivered again during the intratracheal challenge, splenocytes from Alum sensitised animals were challenged with HDM extract as described in the Methods section. This recall challenge method in splenocytes was previously validated by 

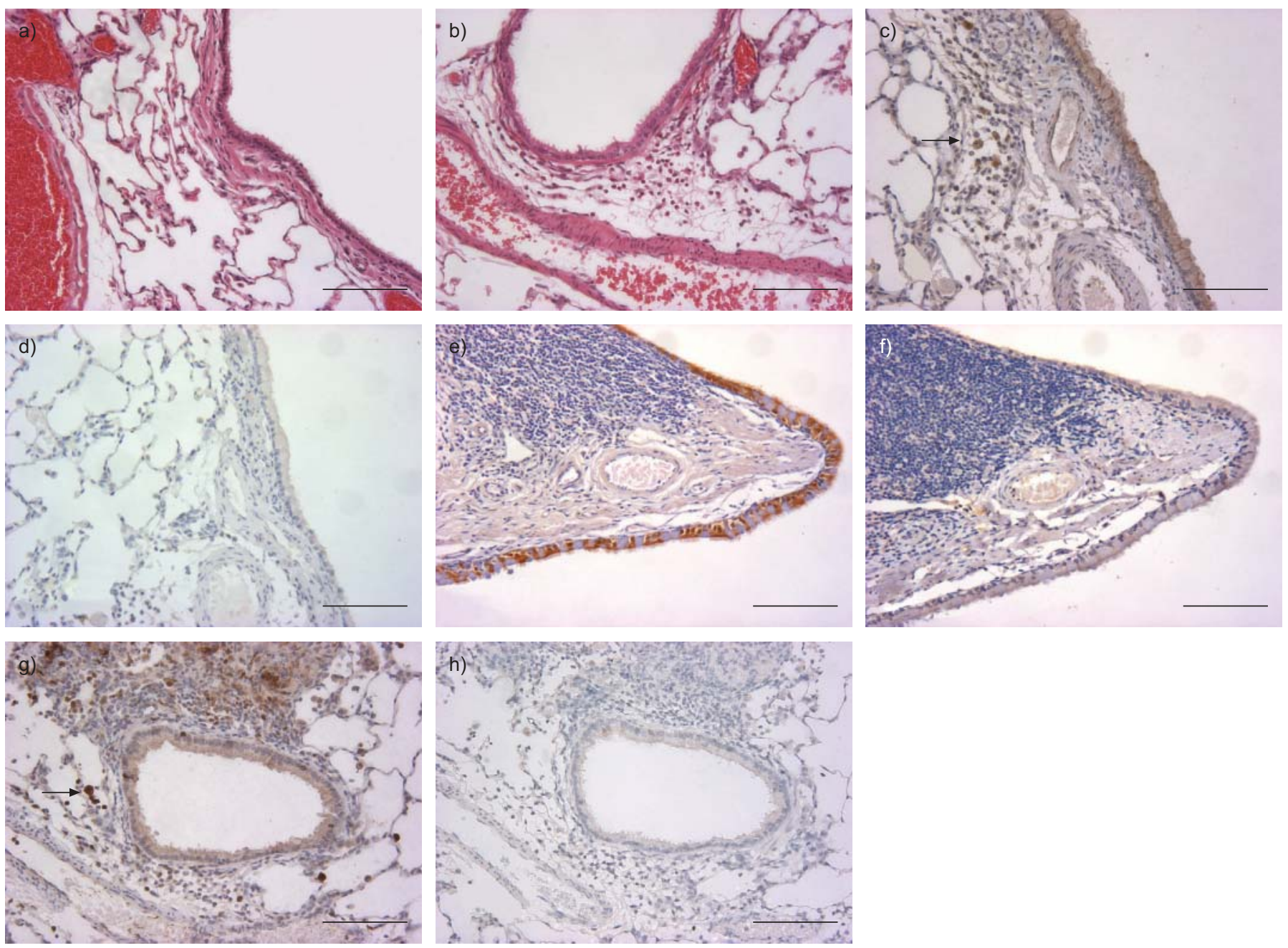

FIGURE 7. Histological examination of lung tissue sections after house dust mite (HDM) challenge. Brown-Norway rats were sensitised with Alum or HDM (5 $\mu$ g, i.p.) plus Alum on days 0 and 14. They were challenged 7 days later with vehicle or HDM (10 $\mu$ gintratracheal). Lung tissue was collected 6 or $48 \mathrm{~h}$ later. a) Haematoxylin and eosin staining of tissue from Alum-only sensitised/saline challenge shows no inflammatory infiltration in the lung parenchyma at $48 \mathrm{~h}$. b) The time-matched Alum-only sensitised/ HDM challenged animals show significant inflammatory infiltration. c) Lung tissue section from nonsensitised/HDM challenged (post- 6 h) animals shows positive staining for interleukin (IL)-13 in the airway epithelium and in inflammatory cells resembling alveolar macrophages (arrow). d) Parallel slide with the blocking peptide present. e, g) Sections are stained for eotaxin and IL-1 $\beta$, respectively. The arrow (g) indicates stained alveolar macrophages. $f, h)$ The parallel slides were stained in the presence of the blocking peptides. Scale bars $=100 \mu \mathrm{m}$.

using splenocytes obtained from an OVA model of allergic inflammation. OVA challenge in splenocytes from OVA sensitised animals caused a release of T-helper (Th)2 cytokines, such as IL-4 $\left(7 \pm 1.1 \mathrm{pg} \cdot \mathrm{mL}^{-1}\right.$ versus control saline challenged $\left.1.2 \pm 0.3 \mathrm{pg} \cdot \mathrm{mL}^{-1} ; \mathrm{p}<0.01\right)$ or IL-13 $\left(27.9 \pm 6.5 \mathrm{pg} \cdot \mathrm{mL}^{-1}\right.$ versus control saline challenged $\left.3.5 \pm 2.4 \mathrm{pg} \cdot \mathrm{mL}^{-1} ; \mathrm{p}<0.01\right)$. However, HDM challenge, even at the top concentration of $50 \mu \mathrm{g} \cdot \mathrm{mL}^{-1}$, failed to cause any significant release of Th2 cytokines from Alum ${ }^{\mathrm{TM}}$-only sensitised splenocytes. These results would support the nonallergic nature of the response observed in Alum $^{\mathrm{TM}}$-only sensitised animals in vivo.

\section{DISCUSSION}

In the current study we have shown that a HDM extract obtained from Der $p$ is able to elicit a direct inflammatory response in the lungs of $\mathrm{BN}$ rats. The inflammation is characterised by neutrophilic and eosinophilic infiltration and associated with an early expression and release of proinflammatory cytokines, such as IL-13, IL-1 $\beta$, eotaxin, MCP-3, TARC and CINC-1. This study demonstrates for the first time that a direct pro-inflammatory effect of HDM, as observed in other studies in vitro [14, 16-20], can also be shown in a more complex biological in vivo setting in the BN rat. However, unlike in previous studies, the inflammation did not appear to be associated with the protease activity of HDM but rather whether or not the animals had received Alum ${ }^{\mathrm{TM}}$ prior to challenge. This would suggest that the direct inflammatory response to inhaled HDM is dependent on a function of Alum $^{\mathrm{TM}}$, such as increasing total IgE.

The study of the early immune events induced by allergens is currently under a great deal of scrutiny as it is probable that they have huge relevance to the pathogenesis of allergendriven inflammatory diseases, such as asthma. These events 

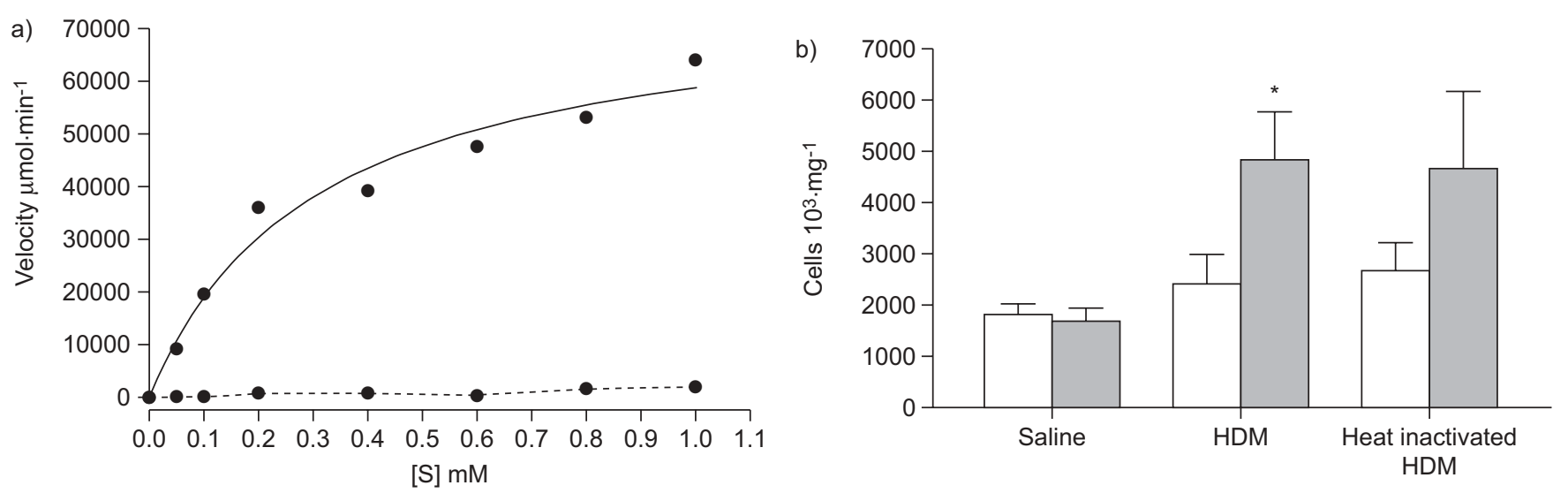

FIGURE 8. The effect of house dust mite (HDM) protease activity on cell recruitment in bronchoalveolar lavage fluid and lung tissue. a) Protease activity in the extract was assessed by a continuous rate (kinetic) assay using the fluorogenic peptide substrate Boc-Gln-Ala-Arg-AMC. Data are fitted to a Michaelis-Menten equation: $\mathrm{y}=\mathrm{V} \times \mathrm{x} /(\mathrm{Km}+\mathrm{x})$. HDM extract (—) showed a positive protease activity with a maximal rate of conversion of 76,636 $\mu \mathrm{mol} \cdot \mathrm{min}^{-1}$ and a Km (Michaelis-Menten constant) of $304.9 \mu \mathrm{M}$. Heat inactivated HDM extract (….......) showed no protease activity. b) Tissue eosinophilia $48 \mathrm{~h}$ after HDM challenge. Alum-sensitised animals ( $\square$ ) showed significant inflammatory infiltration after HDM challenge when compared with saline-sensitised animals $(\square)$. Heat inactivation of the HDM did not change this profile. *: $p<0.05$ compared with relevant control.

have been poorly studied to date and they may be of great importance in the development of the allergic inflammation and our understanding of asthma pathology. It is currently believed that when HDM allergens interact with the bronchial epithelium, they induce direct damage through protease activity, disrupting the epithelial tight junctions and thereby increasing the bronchial epithelium permeability and facilitating trans-epithelial allergen delivery and interaction with antigen presenting cells [5-7]. We have demonstrated that HDM allergens can interact with the lung, particularly the airway epithelium, and induce asthma-like inflammation, i.e. eosinophilia and an increase in Th2 type cytokine profile. What is very interesting is that HDM can elicit these responses in animals which have not been previously exposed to the same antigen. It has been recently reported that certain fungal allergens, with a proteinase activity, are able to induce eosinophilic airway inflammation in mice in the absence of adaptive immune cells. This direct inflammation was reported to be associated with the induction of chemokines, such as MCP-3 (CCL7) and TARC. We observed a similar increase in these two cytokines which might have suggested a similar mechanism could be the cause of the early eosinophilia observed in this study. Furthermore, HeIJINK et al. [20] has shown in vitro that this TARC expression, which may be critical for Th2 cell recruitment in inflammation, can be directly induced by Der $p$ in human bronchial epithelial cells. However, although this could have been a suitable explanation for our results, the fact that the inactivation of the protease activity in the extract does not prevent the development of the inflammatory response suggests a different mechanism. Conversely, it has also been recently reported that nonproteolytic HDM allergens, which could be present in the extract, such as Der $p 2$, are able to induce nuclear factor- $\kappa \mathrm{B}$ and mitogen-activated protein kinase activation [30].

All animals that received Alum ${ }^{\mathrm{TM}}$ during sensitisation, with or without HDM, showed significant increases of serum IgE. This phenomenon is not unique and other inorganic salts, such as $\mathrm{HgCl}_{2}$, have been shown in the past to cause an elevation of total IgE in the BN rat [31]. As expected only the rats that also received HDM during sensitisation showed significant levels of serum HDM-specific IgE. In the rats that did not receive Alum ${ }^{\mathrm{TM}}$, i.e. the ones with lower total $\mathrm{IgE}$, we failed to observe the direct inflammatory response to inhaled HDM. The possible association of serum IgE levels and asthma, independent of specific allergic sensitisation has been previously reported $[32,33]$. Nonatopic asthma accounts for $10-33 \%$ of all asthma sufferers [34]. At the cellular and molecular level, nonatopic asthma and atopic asthma are very similar, and the reason for their clinical difference remains to be fully understood [35]. There is firm evidence that IgEmediated mechanisms are involved not only in the pathogenesis of atopic, but also nonatopic asthma and the elevation of total serum $\operatorname{IgE}$ has been associated with asthma in nonallergic individuals [32, 33]. It has been suggested that in these individuals total $\operatorname{IgE}$ may represent just a consequence of asthma, a marker of allergic inflammation [32]. However, our results would suggest that there is an actual link, and we propose that the development of the inflammatory response seen in our model may be associated with the presence of high levels of total IgE in serum. If our data do translate to the situation in humans, it may explain why this antigen, which is so promiscuous, does not inflame everyone's airways. In fact, our assertion would be someone exposed to HDM would also need to have elevated IgE levels in order to evoke an inflammatory response in the lung. Indeed, a recent study suggests that individuals with $\operatorname{IgE}$ sensitisation to common allergens may develop an asthmatic response to a particular different allergen even though serumspecific IgE levels suggest that they are not sensitised to it [36].

Interestingly, and despite showing an asthma-like inflammatory reaction and HDM-specific $\operatorname{IgE}$, none of the groups studied displayed any changes in airway function after HDM challenge, either early asthmatic response or LAR. However, as shown in previous studies [37, 38], a single HDM challenge 
may not be enough to achieve reliable lung function changes in the rat and indeed it appears that in the mouse models multiple HDM challenges may be necessary [39-41].

One possible caveat to the suggestion that it is the HDM that is directly causing the inflammation is that something else within the HDM mixture is responsible, i.e. the small amount of endotoxin. Furthermore, a recent study proposes that Toll like receptor- 4 receptor activation could play a crucial part in HDM induced responses [41]. Whilst endotoxin can cause some of the inflammation observed in the study we feel it is very unlikely to be responsible. The levels are very low $\left(36 \mathrm{EU} \cdot \mathrm{mL}^{-1}\right.$ as measured with a Pyrogen 5000 LAL endotoxin assay; Cambrex Bioscience Ltd, Wokingham, UK), the time of cellular influx is much later than one would expect after LPS, some of the mediators measured are not thought to be upregulated by endotoxin (i.e. TARC) and, probably most convincingly, there is no inflammation present in the HDM challenged but nonAlum $^{\mathrm{TM}}$ sensitised animals. Another possible explanation is that the Alum ${ }^{\mathrm{TM}}$-only sensitised animals had been exposed to an undefined protein, which was then delivered again during the intratracheal challenge, causing an allergic Th2 response. However, the negative results from the recall challenge experiment would seem to rule out this possibility. Nonetheless, we cannot completely discard that some of the inflammation observed is through a non-HDM mechanism.

In conclusion, these data demonstrate that HDM can, after exposure to an adjuvant which increases serum total $\operatorname{IgE}$, evoke direct inflammation in the airways which in many ways is characteristic of the asthmatic airway. We feel this is a very interesting finding in that it might help unravel the complex association between high IgE levels, atopy and the development of the asthma phenotype. Indeed these data may significantly alter our understanding of the role of $\operatorname{IgE}$ in the pathogenesis of asthma.

\section{SUPPORT STATEMENT}

Funding for the study was provided by GlaxoSmithKline.

\section{STATEMENT OF INTEREST}

Statements of interest for R.G. Knowles and M.G. Belvisi, and for the study itself, can be found at www.erj.ersjournals.com $/ \mathrm{misc} /$ statements.dtl

\section{ACKNOWLEDGEMENTS}

We would like to thank C. Dean (Respiratory Pharmacology, Pharmacology and Toxicology, Imperial College London, Faculty of Medicine, National Heart and Lung Institute, London, UK) for help with the preparation of this manuscript.

\section{REFERENCES}

1 Thomas WR, Smith WA, Hales BJ, et al. Characterization and immunobiology of house dust mite allergens. Int Arch Allergy Immunol 2002; 129: 1-18.

2 Platt-Mills TA. The role of indoor allergens in asthma. Allergy 1995; 50: 5.

3 Platts-Mills TA, Vervloet D, Thomas WR, et al. Indoor allergens and asthma: report of the Third International Workshop. J Allergy Clin Immunol 1997; 100: S2-S24.

4 Takai T, Kato T, Sakata Y, et al. Recombinant Der p 1 and Der $\mathrm{f} 1$ exhibit cysteine protease activity but no serine protease activity. Biochem Biophys Res Commun 2005; 328: 944-952.
5 Herbert CA, King CM, Ring PC, et al. Augmentation of permeability in the bronchial epithelium by the house dust mite allergen Der p1. Am J Respir Cell Mol Biol 1995; 12: 369378.

6 Wan H, Winton HL, Soeller C, et al. Quantitative structural and biochemical analyses of tight junction dynamics following exposure of epithelial cells to house dust mite allergen Der $\mathrm{p} 1$. Clin Exp Allergy 2000; 30: 685-698.

7 Wan H, Winton HL, Soeller C, et al. Der p 1 facilitates transepithelial allergen delivery by disruption of tight junctions. J Clin Invest 1999; 104: 123-133.

8 Sakata Y, Arima K, Takai T, et al. The squamous cell carcinoma antigen 2 inhibits the cysteine proteinase activity of a major mite allergen, Der p 1. J Biol Chem 2004; 279: 5081-5087.

9 Takai $\mathrm{T}$, Kato T, Ota M, et al. Recombinant Der $\mathrm{p} 1$ and Der $\mathrm{f} 1$ with in vitro enzymatic activity to cleave human CD23, CD25 and $\alpha_{1}$ antitrypsin, and in vivo IgE-eliciting activity in mice. Int Arch Allergy Immunol 2005; 137: 194-200.

10 Kikuchi $Y$, Takai T, Ota M, et al. Application of immunoreaction enhancer solutions to an enzyme-linked immunosorbent assay for antigen-specific $\operatorname{IgE}$ in mice immunized with recombinant major mite allergens or ovalbumin. Int Arch Allergy Immunol 2006; 141: 322-330.

11 Furmonaviciene R, Ghaemmaghami AM, Boyd SE, et al. The protease allergen Der $\mathrm{p} 1$ cleaves cell surface DC-SIGN and DCSIGNR: experimental analysis of in silico substrate identification and implications in allergic responses. Clin Exp Allergy 2007; 37: 231-242.

12 Machado DC, Horton D, Harrop R, et al. Potential allergens stimulate the release of mediators of the allergic response from cells of mast cell lineage in the absence of sensitization with antigen-specific IgE. Eur J Immunol 1996; 26: 2972-2980.

13 Peake HL, Currie AJ, Stewart GA, et al. Nitric oxide production by alveolar macrophages in response to house dust mite fecal pellets and the mite allergens, Der p 1 and Der p 2. J Allergy Clin Immunol 2003; 112: 531-537.

14 King C, Brennan S, Thompson PJ, et al. Dust mite proteolytic allergens induce cytokine release from cultured airway epithelium. J Immunol 1998; 161: 3645-3651.

15 Phillips C, Coward WR, Pritchard DI, et al. Basophils express a type 2 cytokine profile on exposure to proteases from helminths and house dust mites. J Leukoc Biol 2003; 73: 165-171.

16 Asokananthan N, Graham PT, Stewart DJ, et al. House dust mite allergens induce proinflammatory cytokines from respiratory epithelial cells: the cysteine protease allergen, Der $\mathrm{p} \mathrm{1,} \mathrm{activates}$ protease-activated receptor (PAR)-2 and inactivates PAR-1. J Immunol 2002; 169: 4572-4578.

17 Hales BJ, Shen H, Thomas WR. Cytokine responses to Der $\mathrm{p} 1$ and Der p 7: house dust mite allergens with different IgE-binding activities. Clin Exp Allergy 2000; 30: 934-943.

18 Sun G, Stacey MA, Schmidt M, et al. Interaction of mite allergens Der P3 and Der P9 with protease-activated receptor-2 expressed by lung epithelial cells. J Immunol 2001; 167: 1014-1021.

19 Adam E, Hansen KK, Astudillo OF, et al. The house dust mite allergen Der p 1, unlike Der p 3, stimulates the expression of interleukin-8 in human airway epithelial cells via a proteinaseactivated receptor-2-independent mechanism. J Biol Chem 2006; 281: 6910-6923.

20 Heijink IH, Marcel Kies P, van Oosterhout AJM, et al. Der p, IL-4, and TGF- $\beta$ cooperatively induce EGFR-dependent TARC expression in airway epithelium. Am J Respir Cell Mol Biol 2007; 36: 351359.

21 Kauffman H, Tamm M, Timmerman JA, et al. House dust mite major allergens Der p 1 and Der p 5 activate human airwayderived epithelial cells by protease-dependent and proteaseindependent mechanisms. Clin Mol Allergy 2006; 4: 5. 
22 Underwood SL, Haddad E, Birrell MA, et al. Functional characterization and biomarker identification in the Brown Norway model of allergic airway inflammation. $\mathrm{Br} J$ Pharmacol 2002; 137: 263-275.

23 Schulz O, Sewell HF, Shakib F. A sensitive fluorescent assay for measuring the cysteine protease activity of Der $p 1$, a major allergen from the dust mite Dermatophagoides pteronyssinus. Mol Pathol 1998; 51: 222-224.

24 Birrell MA, Hardaker E, Wong S, et al. Ік-B kinase-2 inhibitor blocks inflammation in human airway smooth muscle and a rat model of asthma. Am J Respir Crit Care Med 2005; 172: 962-971.

25 McCluskie K, Birrell MA, Wong S, et al. Nitric oxide as a noninvasive biomarker of lipopolysaccharide-induced airway inflammation: possible role in lung neutrophilia. J Pharmacol Exp Therap 2004; 311: 625-633.

26 Lundblad LKA, Irvin CG, Hantos Z, et al. Penh is not a measure of airway resistance! Eur Respir J 2007; 30: 805.

27 Kim EY, Battaile JT, Patel AC, et al. Persistent activation of an innate immune response translates respiratory viral infection into chronic lung disease. Nat Med 2008; 14: 633-640.

28 Allahverdian S, Harada N, Singhera GK, et al. Secretion of IL-13 by airway epithelial cells enhances epithelial repair via HB-EGF. Am J Respir Cell Mol Biol 2008; 38: 153-160.

29 Temann UA, Laouar Y, Eynon EE, et al. IL9 leads to airway inflammation by inducing IL13 expression in airway epithelial cells. Int Immunol 2007; 19: 1-10.

30 Osterlund C, Grönlund H, Polovic N, et al. The non-proteolytic house dust mite allergen Der p 2 induce NF-кB and MAPK dependent activation of bronchial epithelial cells. Clin Exp Allergy 2009; 39: 1199-1208.
31 White KL, David DW, Butterworth LF, et al. Assessment of autoimmunity-inducing potential using the brown Norway rat challenge model. Toxicol Lett 2000; 112-113: 443-451.

32 Sunyer J, Anto JM, Castellsague J, et al. Total serum IgE is associated with asthma independently of specific IgE levels. The Spanish Group of the European Study of Asthma. Eur Respir J 1996; 9: 1880-1884.

33 Beeh KM, Ksoll M, Buhl R. Elevation of total serum immunoglobulin $\mathrm{E}$ is associated with asthma in nonallergic individuals. Eur Respir J 2000; 16: 609-614.

34 Novak N, Bieber T. Allergic and nonallergic forms of atopic diseases. J Allergy Clin Immunol 2003; 112: 252-262.

35 Jayaratnam A, Corrigan CJ, Lee TH. The continuing enigma of non-atopic asthma. Clin Exp Allergy 2005; 35: 835-837.

36 Chinn S, Heinrich J, Anto JM, et al. Bronchial responsiveness in atopic adults increases with exposure to cat allergen. Am J Respir Crit Care Med 2007; 176: 20-26.

37 Singh P, Daniels M, Winsett DW, et al. Phenotypic comparison of allergic airway responses to house dust mite in three rat strains. Am J Physiol Lung Cell Mol Physiol 2003; 284: L588-L598.

38 Dong W, Selgrade MK, Gilmour MI. Systemic administration of Bordetella pertussis enhances pulmonary sensitization to house dust mite in juvenile rats. Toxicol Sciences 2003; 72: 113-121.

39 Fuchs B, Braun A. Improved mouse models of allergy and allergic asthma: chances beyond ovalbumin. Curr Drug Targets 2008; 9: 495-502.

40 Gregory LG, Causton B, Murdoch JR, et al. Inhaled house dust mite induces pulmonary T helper 2 cytokine production. Clin Exp Allergy 2009; 39: 1597-1610.

41 Hammad H, Chieppa M, Perros F, et al. House dust mite allergen induces astham via Toll-like receptor 4 triggering of airway structural cells. Nat Med 2009; 15: 410-416. 